\title{
Industrial and Natural Waste Transformed into Raw Material
}

\author{
C. Costa $^{1}$, M. Monteiro ${ }^{1}$, B. Rangel ${ }^{1}$, JL. Alves $^{2}$ \\ ${ }^{1}$ Faculty of Engineering, University of Porto, Porto, Portugal. \\ ${ }^{2}$ INEGI, Faculty of Engineering, University of Porto, Porto, Portugal.
}

Currently, we live in a world where the materials are the protagonists. Raw materials are fundamental to make industrial products, however the increasing demand for these finite natural resources, put the more industrialized countries under pressure to find ways to recycle and reuse the products at the end of their lives [1]. Every year, tons of industrial and natural waste are accumulated and destroyed without a new use for them. Today, the energy consumption at the world level to extract raw materials contributes significantly to pollution and environmental degradation. In the European Union, the construction sector is responsible for $40 \%$ of global energy consumption, contributing significantly to $\mathrm{CO}_{2}$ emissions [2]. The planet's future is compromised, unless the human being learn how to preserve and chat features, changing the basic patterns of consumption, manufacturing and recycling [3].

Sofas and Wood industries generate significant amounts of waste that undergo a thoughtless destruction or recycling with a final order to reuse. It is urgent to change this situation.

This communication presents the research work that has been conducting in the scope of the Master Program in Product and Industrial Design of Faculty of Engineering, Faculty of Fine Arts and Design Studio FEUP, seeking the reuse of leftovers (textile and wood powder), to create innovative products. The main objective is to prepare the waste that is mixed with different amounts and types of binders, and cast into silicone or resin moulds. In some cases, the introduction of a shape memory alloy or optical fibres can promote an extra value and functionality to the designed products. This way the aim is to sensitize the community to the possibility of introducing new products in the market addressing concepts such as green design, sustainability and innovation.

[1] M. Ashby, K. John, Materials and Design: The art and science of material in product design, Vol. 2, Elsevier, Ed. (Oxford, 2010).

[2] A. Barroso, A. Camões, R. Frangueiro, R. Eires, S. Cunha, M. Kheradmand, Materiais de Construção Sustentáveis, Vol. 1, Universidade do Minho, Ed. (Braga, 2014).

[3] V. Papanek, Arquitectura e Design: Ecologia e Ética, E. 70, Ed. (Lisboa, 1995). 